\title{
Oesophageal cancer and gastro- oesophageal reflux: what is the relationship?
}

\section{J Lagergren}

There seems to be a causal link between reflux and oesophageal adenocarcinoma, and Barrett's oesophagus is very likely an important, and possibly necessary, link in the causal pathway from reflux to oesophageal adenocarcinoma

$\mathrm{T}$ he direct relation between reflux and adenocarcinoma of the oesophagus has recently been addressed in several well designed population based epidemiological studies, using different study designs. ${ }^{1-5}$ The studies are all in agreement that reflux is associated with an increased risk of oesophageal adenocarcinoma in a seemingly dose dependent manner. ${ }^{1-5}$

The specific role of Barrett's oesophagus for this association was not addressed in these studies but the presence of Barrett's oesophagus has been regarded as a potential link in the causal pathway. More speculatively, based on an interpretation of the results from a large population based study in Sweden, we hypothesised that the relation between reflux and oesophageal adenocarcinoma might be independent of Barrett's oesophagus. ${ }^{2}$ This hypothesis was based on two findings of our study. Firstly, among patients with a history of severe and longstanding reflux symptoms, the association with adenocarcinoma was of similar strength as that of the association previously reported between the occurrence of Barrett's oesophagus and the risk of oesophageal adenocarcinoma in large scale studies. $^{6-9}$ Secondly, when we compared our case patients with oesophageal adenocarcinoma who had a verified Barrett's oesophagus with those who had no such mucosa detected during endoscopy or surgery, we found that the association between reflux and oesophageal adenocarcinoma was equally strong. The possibility of tumour overgrowth covering the Barrett might explain this finding, however. Nevertheless, the hypothesis deserves further attention.

In this issue of Gut, SolaymaniDodaran and colleagues ${ }^{10}$ address the role of Barrett's oesophagus compared with the role of reflux per se in the aetiology of oesophageal adenocarcinoma in an interesting investigation [see page 1070]. They analysed the strength of the association with adenocarcinoma in three cohorts of patients, including a cohort of patients with Barrett's oesophagus, a cohort of patients with oesophagitis, and third cohort of patients representing simple reflux. As a reference, a comparison cohort of patients without any of these conditions was selected. The point estimate of the relative risk of oesophageal cancer was 10 in the Barrett's cohort while the corresponding risk estimates were approximately 2 in the two cohorts representing reflux without Barrett's metaplasia. The authors conclude that their findings do not support the fact that gastro-oesophageal reflux in itself predisposes to oesophageal cancer. This interpretation is not necessarily true, however. There are some problems that deserve consideration in their study.

Firstly, the study included oesophageal cancers of any histological type in the analysis (that is, it did not specifically address the risk of adenocarcinoma of the oesophagus, the only type of oesophageal cancer that has been linked with reflux). Secondly, the risk of chance errors was high as the study, like most other prospective studies of this relatively rare disease, was underpowered. The limited number of 43 cases of oesophageal cancer were evaluated, and among these cancers the oesophageal squamous cell carcinomas and any other types were included. Thirdly, selection bias in the comparisons between the cohorts might explain the differences between the three cohorts reported in the study. The cohort representing Barrett's oesophagus is likely to consist of patients with the most severe and longstanding reflux disease compared with the two comparison cohorts representing oesophagitis and simple reflux. From previous studies, we know that the relationship between reflux and oesophageal adenocarcinoma is strongly dose dependent both with regard to severity and duration of reflux (the relative risk of this cancer was 43.5 among patients with long term and severe symptoms in our Swedish investigation $^{2}$ ). We also know that patients who develop Barrett's oesophagus usually have had reflux symptoms for long periods of time, typically for decades. The other two cohorts in the study by Solaymani-Dodaran and colleagues ${ }^{10}$ are likely to encompass those with, on average, less severe and less longstanding reflux. Any differences between reflux cohorts in the study are likely to be strongly affected by such selection bias. Hence the study cannot reliably verify whether or not Barrett's oesophagus is a mandatory step in the development of adenocarcinoma of the oesophagus.

In summary, based on the current knowledge, there seems to be a causal link between reflux and oesophageal adenocarcinoma. Barrett's oesophagus is very likely an important, and possibly necessary, link in the causal pathway from reflux to oesophageal adenocarcinoma but more studies are needed before the true answer to this important and interesting question can be established.

Gut 2004;53:1064-1065.

doi: 10.1136/gut.2003.038471

Correspondence to: Professor J Lagergren, Department of Surgery, Karolinska University Hospital, Stockholm SE-171 76, Sweden; jesper.lagergren@kus.se

\section{REFERENCES}

1 Chow WH, Finkle WD, McLaughlin JK, et al. The relation of gastroesophageal reflux disease and its treatment to adenocarcinomas of the esophagus and gastric cardia. JAMA 1995;274:474-7.

2 Lagergren J, Bergström R, Lindgren A, et al. Symptomatic gastroesophageal reflux as a risk factor for esophageal adenocarcinoma N Engl J Med 1999;340:825-31.

3 Farrow DC, Vaughan TL, Sweeney C, et al. Gastroesophageal reflux disease, use of $\mathrm{H} 2$ receptor antagonists, and risk of esophageal and gastric cancer. Cancer Causes Control 2000;11:231-8

4 Ye W, Chow WH, Lagergren J, et al. Risk of adenocarcinomas of the oesophagus and gastric cardia in patients with gastrooesophageal reflux diseases and after antireflux surgery. A nationwide cohort study in Sweden. Gastroenterology 2001;121:1286-93.

5 Wu AH, Tseng CC, Bernstein L. Hiatal hernia, reflux symptoms, body size, and risk of esophageal and gastric adenocarcinoma. Cancer 2003;98:940-8.

6 Spechler SJ, Robbins AH, Rubins HB, et al. Adenocarcinoma and Barrett's esophagus. An 
overrated risk. Gastroenterology

1984;87:927-33.

7 Cameron AJ, OH BJ, Payne WS. The

incidence of adenocarcinoma in columnar-lined

(Barrett's) esophagus. N Engl J Med

1985;314:857-8.
8 Van Der Veen AH, Dees J, Blankenstein JD, et al. Adenocarcinoma in Barrett's esophagus: an overrated risk. Gut 1989;10:16-18.

9 Drewitz DJ, Sampliner RE, Garewal HS. The incidence of adenocarcinoma in Barrett's esophagus: a prospective study of 170 patients followed 4.8 years. Am J Gastroentero 1997;92:214-15.

10 Solaymani-Dodaran M, Logan RFA, West J, et al. Risk of oesophageal cancer in Barrett's oesophagus and gastro-oesophageal reflux. Gut 2004;53:1070-74
Coeliac disease

\section{T helper cell polarisation in coeliac disease: any (T-)bet?}

M H Holtmann, M F Neurath

Recent data strongly support the view that coeliac disease is a Th1 mediated inflammatory disease as both interferon $\gamma$ production and T-bet levels in gut infiltrating cells are upregulated

$\mathrm{T}$ he puzzling observation on high interferon $\gamma$ (IFN- $\gamma)$ but low interleukin (IL)-12 levels in coeliac disease (CD) has resulted in questions about the underlying principles of $\mathrm{T}$ helper cell polarisation. In this issue of Gut, ${ }^{1}$ the molecular basis of $\mathrm{T}$ helper cell polarisation in $\mathrm{CD}$ has been illuminated by the finding that T-bet, the master transcription factor of $\mathrm{T}$ helper cell type l (Thl) cells, is upregulated in this disease [see page 1090].

The past decade has witnessed a dramatic improvement in our pathophysiological understanding of inflammatory disorders of the intestinum due to extensive research efforts focusing on regulatory mechanisms of the immune system. This has been greatly facilitated by the advent of molecular biological techniques which have allowed for the identification and characterisation of distinct factors in the complex regulatory network of the immune system. General themes have thus been recognised and an attempt is being made to classify diseases according to common immunological features.

One crucial emerging theme is the Th1/Th2 polarisation of T helper cells. ${ }^{2}{ }^{3}$ On activation with distinct immunological stimuli, naive $\mathrm{CD}^{+}$precursor $\mathrm{T}$ helper cells differentiate into mature $\mathrm{T}$ cells which either produce a so called Thl cytokine profile characterised by tumour necrosis factor $\alpha$ (TNF- $\alpha)$ and IFN- $\gamma$, or a T helper cell type 2 (Th2) cytokine profile including IL-4, IL-5, IL-9, and IL-13. While these $\mathrm{T}$ cell subsets produce proinflammatory cytokines that can cause substantial tissue injury in vivo, more recent data suggest that additional subsets of $\mathrm{CD} 4^{+} \mathrm{T}$ helper cells exist with anti-inflammatory functions. These subsets include $\mathrm{T}$ helper 3 (Th3) cells producing transforming growth factor $\beta$ (TGF- $\beta$ ), Trl cells producing IL-10, and $\mathrm{CD} 25^{+} \mathrm{CD} 4^{+}$regulatory $\mathrm{T}$ cells (Treg) expressing the master transcription factor Foxp3. ${ }^{45}$

Like all mucosal surfaces, the intestinal mucosa possesses a special immune system (gut associated lymphoid tissue (GALT)) that can be considered the biggest immune system of the body due to its large surface of several hundred square metres of human gut. The immune system of the upper gastrointestinal tract is physiologically exposed to a large amount of antigens from food, such as gluten, which is the protein fraction of wheat (here called gliadin), rye, and barley, and causes the stickiness of these cereals thus allowing the baking of bread.

Normally, ingestion of food antigens such as gliadin does not elicit an immune response. Otherwise, this would be detrimental because it would lead to a permanent state of inflammation of the bowel considering the large amount of food antigens. The intestinal immune system in general is characterised by a hyporesponsive state, which should not be mistaken for passive toleration, but should rather be considered as active inhibition of intestinal immune responses. ${ }^{5}$ Physiologically, an anti-inflammatory cytokine milieu prevails in the intestinal immune system with a predominance of Th3 and Treg T cells that contribute, together with other factors, to this hyporesponsive state. In $\mathrm{CD}$, this hyporesponsiveness to gliadin is abrogated. While the initial pathogenetic steps have been fairly well characterised, details of the downstream immune response involving specific $B$ and $\mathrm{T}$ cell responses are still a matter of debate.

The first report on a malabsorption syndrome on ingestion of wheat that resembles $\mathrm{CD}$ dates back to Aretaeus from Cappadocchia, 2nd century $\mathrm{AD} .{ }^{8}$ In 1888, Gee gave the first detailed clinical description of the "coeliac affection". " Today, CD can be considered as a model disease with autoimmune characteristics for several reasons. ${ }^{10}$ In contrast with most other autoimmune disorders, in $\mathrm{CD}$ an unequivocal trigger (the cereal protein gliadin) has been identified. The antigenicity can be related to a $33 \mathrm{mer}$ epitope that is generated by digestion with intestinal enzymes. ${ }^{11}$ In addition, there is an established close genetic association with the HLA haplotypes DQ2, found in $95 \%$ of patients, or DQ8 found in most of the remaining patients. A highly specific humoral autoimmune response with autoantibodies (IgA antiendomysial antibodies), with almost $100 \%$ sensitivity and specificity to endogenous tissue transglutaminase (tTG), is elicited. ${ }^{12}$

tTG is a calcium dependent ubiquitous enzyme that cross links matrix proteins and thus stabilises connective tissue. ${ }^{13}$ Gliadins, which are glutamine rich $(>30 \%)$, are preferred substrates for tTG as donor substrates and substrate specificity is particularly high for the recently identified 33mer key epitope. Deamidation leads to gliadingliadin cross links and glutamine transfer to proteins in the extracellular matrix which probably generates additional antigenic epitopes. In addition, in the absence of glutamyl acceptor proteins, tTG can deamidate glutamine residues thus converting them into negatively charged glutamic acid. ${ }^{14}$ These modified gliadin peptides have a higher affinity to the coeliac specific HLA-DQ2 molecules than their nondeamidated precursors and can thus elicit a much stronger specific immune response. $^{15}$

A recent model proposes that autoreactive B cell clones specific for tTG or 
tTG-gliadin complexes can bind tTG or tTG-gliadin complexes via their B cell receptors and thus present these antigens to $\mathrm{CD}^{+}{ }^{\mathrm{T}}$ cells via their HLA-DQ2 or HLA-DQ8. ${ }^{16}$ However, it is unclear whether these T cells specific for tTG or tTG-gliadin complexes, respectively, display Thl or Th2 properties. On the one hand, it was shown in this in vitro model system that these $\mathrm{T}$ cells secrete Th2 cytokines such as IL-4 and thus promote expansion and autoantibody production of autoreactive B cells. On the other hand, when lamina propria $\mathrm{T}$ cells were isolated from the small intestine of untreated patients with $\mathrm{CD}$, production of IFN- $\gamma$ was more than 1000-fold increased, consistent with a Thl cytokine response, while IL-4 levels were below the level of detection. ${ }^{17}$ In patients treated with a gluten free diet, IFN $-\gamma$ production was as low as in healthy controls but could be stimulated in vitro by gluten up to levels of untreated patients. Release of IFN- $\gamma$ is most likely pathogenetically relevant as neutralisation of IFN- $\gamma$ prevented gliadin mediated morphological changes in an ex vivo organ culture of treated CD biopsies. $^{18}$

In addition, a Thl response with production of TNF- $\alpha$ represents an important link between $\mathrm{T}$ cell activation and mucosal transformation seen in active coeliac disease. TNF- $\alpha$ activates intestinal fibroblasts to secrete matrix metalloproteinases that are upregulated in $\mathrm{CD}^{19}$ and may cause destruction of connective tissue. ${ }^{18}$ In addition, fibroblasts release keratinocyte growth factor which is an important epithelial mitogen and may lead to hyperplasia of crypt epithelial cells in $\mathrm{CD}^{20}$ One puzzling result however was that IL-12, a key cytokine in the Thl response, was virtually absent in $\mathrm{CD} .{ }^{17}$ The absence of IL- 12 cast doubt on the classification of $\mathrm{CD}$ as a Thl mediated disease because IL-12 has been shown to be crucial for differentiation of naive $\mathrm{T}$ cells into Thl cells and for development of another Thl mediated disease, Crohn's disease, in an experimental in vivo model system for chronic intestinal inflammation..$^{21}$ Furthermore, Crohn's disease is associated with mucosal $\mathrm{T}$ cells expressing large amounts of the IL-12R beta2 chain and the IL-12 inducible transcription factor STAT- $4 .^{23}$

In their work, presented in this issue of Gut, Monteleone and colleagues ${ }^{1}$ provide new data that strongly support the assignment of $\mathrm{CD}$ to the group of Thl mediated diseases. Their approach was to reveal a Thl or Th2 commitment of $\mathrm{CD}^{+} \mathrm{T}$ cells in the mucosa of patients with $\mathrm{CD}$, upstream of the phenotype defining cytokine production of these cells, by looking at the level of transcription and signalling factors that regulate $\mathrm{T}$ cell differentiation into Th1 or Th2 cells, respectively.

IL- 12 is produced by antigen presenting cells and induces generation of the Thl subset with production of IFN $-\gamma .^{24}$ For this, activation and phosphorylation of the transcription factor STAT-4 (signal transducer and activator of transcription 4) is required, as shown by studies in STAT-4 knockout mice. However, STAT-4 in vivo can be activated by IL-12 p35/p40 or heterodimeric IL-23p19/p40, which shares the p40 subunit with IL- $12^{25}$. Another important signalling factor for $\mathrm{T}$ cells is STAT- 1 which is specifically activated by IFN- $\gamma$ rather than IL-12 signalling. ${ }^{26}$ Some IFN $-\gamma$ production is retained in STAT-4 and STAT-l deficient T cells, ${ }^{27}{ }^{28}$ however, suggesting the existence of alternative compensatory pathways. Considering these exceptions from the rule, IL- 12 signalling via STAT-4 appears to be insufficient to define T cells as Thl cells. But are there better markers for $\mathrm{CD}$ ?

Recently, T-bet, a novel member of the T-box family of transcription factors, has been identified. ${ }^{29}$ T-bet not only directs Thl lineage commitment but is also essential for IFN- $\gamma$ production in $\mathrm{CD}^{+}{ }^{+}$but not $\mathrm{CD}^{+}{ }^{+}$T cells. ${ }^{30}$ Of note, for Thl commitment of $\mathrm{T}$ cells, $\mathrm{T}$-bet acts early in the regulatory pathway upstream of IL-12 dependent selection. ${ }^{31}$ The effect of T-bet to enforce Thl commitment of $\mathrm{T}$ cells is so strong that IFN- $\gamma$ production can be induced in fully polarised Th2 cells by retroviral transduction with T-bet. ${ }^{29} 32$

There are also factors that specifically regulate Th2 differentiation. The transcription factor GATA-3 is expressed selectively in Th2 cells and acts via chromatin remodelling and promoter transactivation thus promoting expression of specific Th2 cytokines such as IL-4, IL-5, and IL-13. ${ }^{33}$ STAT-6 is less specific but ectopic expression of STAT-6 can induce expression of Th2 specific cytokines and transcription factors in developing Thl cells. ${ }^{34}$

Monteleone and colleagues ${ }^{1}$ therefore correctly concluded that the balance between STAT-4/T-bet and STAT-6/ GATA-3 seems to dictate the fate of $\mathrm{T}$ cell polarisation and have therefore analysed expression of T-bet, active STAT-4, GATA-3, and active STAT-6 in CD.

Biopsies were taken from the distal duodenum of 18 patients with untreated CD who were all positive for antiendomysial and antitransglutaminase antibodies, from eight treated patients who were in clinical and histological remission, and from 27 normal controls. To confirm that CD lesions are associated with a Thl immune response, mRNA transcripts for IFN- $\gamma$ and IL-4 were analysed in lamina propria mononuclear cells by quantitative polymerase chain reaction. As expected, IFN- $\gamma$, but not IL-4, was significantly upregulated at the mRNA level in mononuclear cells from CD lesions.

Expression of T-bet, STAT-4, GATA-3, and STAT-6 was analysed in whole biopsy homogenates at the protein level by western blotting. The authors were able to show that T-bet is significantly upregulated in the mucosa of patients with untreated CD but is downregulated after a gluten free die to levels comparable with healthy controls. Interestingly, STAT- 4 was not upregulated in patients with untreated CD. Examination of the Th2 transcription factors GATA-3 and STAT- 6 revealed that these factors are not regulated differentially in CD.

The authors then investigated, in functional in vitro studies, whether upregulation of T-bet is a specific response to the external trigger of $\mathrm{CD}$, gliadin. In fact, stimulation of duodenal specimens from patients with treated CD, but not from healthy controls, led to upregulation of T-bet. This upregulation of T-bet was mediated by STAT-1 and could be blocked by inhibition of STAT- 1 .

T-bet is a strong regulator of IFN- $\gamma$ production. Of note, it seems that conversely, expression of T-bet can also be regulated by IFN- $\gamma$ mediated via STAT-1. This is interesting as T-bet acts at a very early stage in the regulatory pathway of Thl commitment of $\mathrm{T}$ cells while IFN- $\gamma$ production represents the functional phenotype of these cells.

The authors point to the limitation of their work which is that analysis of transcription factors was performed in whole biopsies and not in purified cell types. This might raise the concern that upregulation of T-bet could reflect increased infiltration of the mucosa by mononuclear cells rather than a true upregulation of T-bet in these cells. However, the fact that STAT-4 is not upregulated speaks against this explanation. Nevertheless, these findings are interesting. In fact, these data strongly support the view that $C D$ is a Thl mediated inflammatory disease as both IFN- $\gamma$ production and T-bet levels in gut infiltrating cells are upregulated. The lack of STAT-4 upregulation fits to the reported absence of IL-12 in CD (see above). It thus seems that there is an alternative regulatory pathway for Thl differentiation that starts from activation of T-bet but then bypasses STAT-4 and IL-12. It is thus tempting to speculate that T-bet activation in $C D$ is induced or maintained by other cytokines beyond IL-12, such as IL-23 or 
IL-27. Further studies are necessary to address this point.

What is the relevance of this work? Analysis of pathomechanisms at the molecular level provides the potential for novel effective treatment strategies. The clear cut classification of Crohn's disease as a Thl mediated disease with the elucidation of the pivotal pathogenetic role of $\mathrm{TNF}-\alpha$ has led to the development of innovative anti-TNF strategies by recombinant monoclonal antibodies. In CD, there is little need for effective anti-inflammatory treatment, however, as elimination of the exogenous trigger by a gluten-free diet may lead to clinical, histomorphological, and immunological recovery.

Other questions are clinically more relevant. There must be variable environmental factors to explain why clinical manifestations can range from asymptomatic to severe malabsorption. CD is associated with a high prevalence of various other autoimmune disorders such as type 1 diabetes, dermatitis herpatiformis, autoimmune thyroiditis, collagen diseases, autoimmune alopecia, and autoimmune hepatitis. ${ }^{35}$ In $35 \%$ of patients in whom CD is diagnosed at age 20 years or older, including subclinical forms, these associated autoimmune disorders can be found. In patients who have been treated properly with a gluten free diet from infancy, the prevalence is only $5 \%$. Clinically, there may be a need for effective screening methods to detect patients with subclinical CD.

Assignment of $\mathrm{CD}$ to the Thl mediated diseases is of great scientific interest. The unique features of $\mathrm{CD}$ as a model autoimmune disease will facilitate clinical investigation of more general mechanisms of Thl mediated diseases. The Th1/Th2 paradigm may, like all paradigms in science, be only temporary, and will probably give way to novel paradigms as research and science progress in the future. For time being, however, the Thl/Th2 paradigm is helpful in defining immunological disorders $^{2-4} 3637$ with the prospect of developing effective novel treatment approaches.

Gut 2004;53:1065-1067.

doi: $10.1136 /$ gut.2003.038232

\section{Authors' affiliations \\ M H Holtmann, M F Neurath, 1st Departmen \\ of Medicine, Johannes Gutenberg-University, \\ Mainz, Germany}

Correspondence to: $\operatorname{Dr} M F$ Neurath Laboratory of Immunology, I Medical Clinic, University of Mainz, 55131 Mainz, Langenbeckstrasse 1, Germany; neurath@1-med.klinik.uni-mainz.de

\section{REFERENCES}

1 Monteleone I, Monteleone G, Del Vecchio Blanco $G$, et al. Regulation of the Thelper cell type 1 transcription factor T-bet in coeliac disease mucosa. Gut 2004;53:000-0.

2 Glimcher LH, Murphy KM. Lineage commitment in the immune system: the T helper lymphocyte grows up. Genes Dev 2000;14:1261-70.

3 Murphy K, Reiner S. The lineage decisions of helper T cells. Nat Rev Immunol 2002:2:33-44.

4 Mosmann TR, Sad S. The expanding universe of T-cell subsets: Th1, Th2 and more. Immunol Today 1996;17:138-46.

5 Maloy KJ, Powrie F. Regulatory T cells in the control of immune pathology. Nature Immunol 2001;2:1061-6.

6 Boirivant M, Pica R, DeMaria R, et al. Stimulated human lamina propria $T$ cells manifest enhanced Fas-mediated apoptosis. J Clin Invest 1996:98:2616-22.

7 Targan SR, Deem RL, Liu M, et al. Definition of a lamina propria T cell responsive state. Enhanced cytokine responsiveness of $T$ cells stimulated through the CD2 pathway. J Immunol 1995; 154:664-75.

8 Thomas C. On the coeliac affection. In: Major RH, ed. Classic descriptions of disease. Springfield: Charles C Thomas, 1945:600-1.

9 Gee S. On the coeliac affection. St Bartholomews Hosp Rep 1888;24:17-20.

10 Schuppan D. Current concepts of celiac disease pathogenesis. Gastroenterology 2000:119:234-42.

11 Shan L, Molberg O, Parrot l, et al. Structural basis for gluten intolerance in celiac sprue. Science 2002;297:2275-9.

12 Dieterich W, Ehnis T, Bauer M, et al. Identification of tissue transglutaminase as the autoantigen of celiac disease. Nat Med 1997;3:797-801.

13 Greenberg CS, Birkbichler PJ, Rice RH Transglutaminases: multi-functional cross-linking enzymes that stabilize tissues. FASEB $J$ 1991;5:3071-7.

14 Moberg O, Mcadam SN, Korner R, et al. Tissue transglutaminase selectively modifies gliadin peptides that are recognizes by gut-derived T cells in celiac disease. Nat Med 1998:4:713-17.

15 Van de Wal Y, Kooy Y, van Veelen P, et al. Selective deamidation by tissue transglutaminase strongly enhances gliadin-specific $T$ cell reactivity. J Immunol 1998:161:1585-8.

16 Sollid LM. Autoantibodies in coeliac disease: tissue transglutaminase-guilt by association? Gut 1997;47:851-2

17 Nilsen EM, Jahnsen FL, Lundin KE, et al. Gluten induces an intestinal cytokine response strongly dominated by interferon gamma in patients with celiac disease. Gastroenterology 1998; 115:551-63.

18 Pender SL, Tickle SP, Docherty AJ, et al. A major role for matrix metalloproteinases in T cell injury in the gut. J Immunol 1997;158:1582-90.
19 Daum S, Baver U, Foss HD, et al. Increased expression of mRNA for matrix metalloproteinase- 1 and -3 and tissue inhibitor of metalloproteinase-1 in intestinal biopsy specimen from patients with coeliac disease. Gut 1999:44:17-25.

20 Bajaj-Elliot $M$, Poulsom R, Pender SL, et al. Interactions between stromal cell-derived keratinocyte growth factor and epithelial transforming growth factor in immune-mediated crypt cell hyperplasia. J Clin Invest 1999; 102:1473-80.

21 Rengarajan J, Szabo SJ, Glimcher LH. Transcriptional regulation of Th1/Th2 polarization. Immunol Today 2000;21:479-83.

22 Neurath M, Weigmann B, Finotto S, et al. The transcription factor T-bet regulates mucosal $\mathrm{T}$ cell activation in experimental colitis and Crohn's disease. J Exp Med 2002;195: 1 1 29-43.

23 Parrello T, Monteleone G, Cucchiara S, et al. Upregulation of the IL-12 receptor beta 2 chain in Crohn's disease. J Immunol 2000;165:7234-9.

24 Magram J, Connaughton SE, Warrier RR, et al. IL-12-deficient mice are defective in IFN gamma production and type 1 cytokine responses. Immunity 1996;4:471-81

25 Oppmann B, Lesley R, Blom B, et al. Novel p19 protein engages IL-12p40 to form a cytokine, IL23 , with biological activities similar as well as distinct from IL-12. Immunity 2000;13:715-25.

26 Szabo SJ, Sullivan BM, Peng SL, et al. Molecular mechanism regulating $T h 1$ immune response. Annu Rev Immunol 2003;21:713-58.

27 Carter LL, Murphy KM. Lineage-specific requirement for signal transducer and activator of transcription Stat4 in interferon-gamma production form CD4(+) versus CD8(+) T cells. J Exp Med 1999;189:1355-60.

28 Durbin JE, Hackenmiller R, Simon MC, et al. Targeted disruption of the mouse STATl gene results in compromised innate immunity to viral disease. Cell 1996;84:443-50.

29 Szabo SJ, Kim ST, Costa GL, et al. A novel transcription factor, T-bet, directs Th1 lineage commitment. Cell 2000;100:655-69.

30 Szabo SJ, Sullivan BM, Stemmann C, et al. Distinct effects of T-bet in TH1 lineage commitment and IFN-gamma production in CD4 and CD8 T cells. Science 2002;295:338-41.

31 Mullen AC, High FA, Hutchins AS, et al. Role of Tbet in commitment of $\mathrm{TH} 1$ cells before IL-12 dependent selection. Science 2001;292:1907-10.

32 Afkarian M, Sedy JR, Yang J, et al. T-bet is a STAT1-induced regulator of IL-12R expression in naive CD4+ T cells. Nat Immunol 2002;3:549-57

33 Zheng W, Flavell RA. The transcription factor GATA-3 is necessary and sufficient for Th2 cytokine gene expression in CD4+ T cells. Cell 1997; 89:587-96.

34 Kurata H, Lee HJ, O'Garra A, et al. Ectopic expression of activated STAT- 6 induces the expression of Th2-specific cytokines and transcription factors in developing Th1 cells. Immunity 1999;1 1:677-88.

35 Ventura A, Magazzu G, Greco L. Duration of exposure to gluten and risk for autoimmune disorders in patients with celiac disease. Gastroenterol 1999;117:297-303.

36 Neurath MF, Finotto S, Glimcher LH. The role of Th1/Th2 polarization in mucosal immunity. Nature Med 2002;8:567-73.

37 Finotto S, Neurath MF, Glickman JN, et al. Development of spontaneous airway changes consistent with human asthma in mice lacking T-bet. Science 2002;295:336-8. 
Irritable bowel syndrome

\section{East meets West: infection, nerves, and mast cells in the irritable bowel syndrome}

\section{S M Collins, G Barbara}

The incidence of irritable bowel syndrome following acute gastroenteritis in China is similar to that reported in the UK and North America

$\mathrm{T}$ he irritable bowel syndrome (IBS) is the most common gastroenterological disorder seen in Western societies where it imposes a major socioeconomic burden. ${ }^{1}$ The economic impact of IBS arises, at least in part, from difficulties in diagnosis and treatment, which in turn reflect our limited conceptualisation of this disorder. Recent studies have identified acute bacterial gastroenteritis as a strong risk factor for the development of IBS $^{2}$ but evidence supporting this relationship is limited to studies performed in Western countries. ${ }^{3-7}$

Although IBS has received less attention in non-Western countries, available data suggest that it is common in the African continent, ${ }^{8-10}$ Malaysia, ${ }^{11}$ and China $^{12}$ where the condition is significantly underdiagnosed by Western practitioners. ${ }^{13}$ This hesitation in diagnosing IBS in Eastern countries likely reflects uncertainty regarding the influence of culture and endemic infection on the clinical expression of IBS in these countries. Indeed, in countries where enteric parasitic infestation is common, there is controversy regarding the role of infection in the development of IBS, as eradication of the parasite may not improve IBS symptoms. ${ }^{14}$ However, studies in animal models suggest that the host response to the initial infection is a critical determinant of persistent gut dysfunction, and the continued presence of the parasite is not necessary for induction of a chronic dysfunctional state. ${ }^{15}$ Thus the role of infection in the pathogenesis of IBS in these countries may be underestimated.

It is on this background of uncertainty that the paper by Wang and colleagues, ${ }^{16}$ published in this issue of Gut, is received with considerable interest [see page 1096]. This cohort study evaluated gastrointestinal symptoms in 295 patients recovering from acute gastroenteritis in Beijing, China. During a 1-2 year follow up period, the authors found an $8.1 \%$ incidence of IBS among all patients compared with $0.8 \%$ of controls, and an incidence of $10.2 \%$ of IBS in those patients (71.4\%) who had a documented Shigella infection. The authors also found that $22.4 \%$ of patients ( $v 7.4 \%$ of controls) exhibited functional gastrointestinal symptoms that did not meet the Rome II criteria. These results indicate that the incidence of chronic gastrointestinal symptoms following acute gastroenteritis is similar to that reported in the UK and North America. ${ }^{3-7}$ The study by Wang and colleagues $^{16}$ also provides the first positive association between Shigella infection and IBS, as pathogens reported in previous studies were Salmonella and Campylobacter. Taken together, these observations suggest that host, rather than microbial, factors influence the development of post-infective IBS (PIIBS), although Campylobacter toxin may also contribute to the pathogenesis of PI-IBS. ${ }^{17}$ As in previous studies, the severity of the acute infection was found to be a strong risk factor for the development of PI-IBS. ${ }^{4}{ }^{7}$ In contrast with a significant predisposition of females in Western studies, the study of Wang and colleagues ${ }^{16}$ did not identify sex as a risk factor for PI-IBS, and this is in keeping with other IBS studies from Asia. ${ }^{18}$ A UK study has shown that $>50 \%$ of IBS patients remain symptomatic six years post-gastroenteritis ${ }^{19}$ and it would be of interest to determine whether there is a similar prognosis in the Beijing patients.

The study by Wang and colleagues ${ }^{16}$ confirmed and extended the findings from Western studies, indicating that low grade inflammation is present in patients with PI-IBS. Increased expression of interleukin (IL)-1 $\beta$ mRNA in rectal biopsies of PI-IBS patients confirms the recent observations of Gwee and colleagues. ${ }^{20}$ The authors also found increased IL- $1 \beta$ expression in the terminal ileum. ${ }^{16}$ Western studies on PI-IBS patients have been restricted to the rectosigmoid region and have not found increased mast cell numbers. ${ }^{41}$ However, previous studies found increased numbers of mast cells in the caecum, ${ }^{22}$ terminal ileum, ${ }^{23}$ and descending colon ${ }^{24}$ of IBS patients although it is not known how many of those patients had a history of gastroenteritis at the onset of IBS. Spiller et al found increased numbers of intraepithelial lymphocytes and $\mathrm{T}$ lymphocytes, but not mast cells, in the rectosigmoid region of PI-IBS patients ${ }^{21}$ and suggested that these histological findings could distinguish between IBS of infective and idiopathic aetiologies. ${ }^{25}$ As these studies were conducted on Western patients, it is not known whether the discrepancy in mast cell number in PI-IBS patients observed in the studies from the UK and Beijing reflect differences in patient recruitment, tissue sampling or processing, or an important biological variable related to either the infective agent or differences, for example, in microflora. Further studies are clearly necessary.

The immunohistochemical studies reported by Wang and colleagues ${ }^{16}$ were performed on a mixed group of IBS patients that met the Rome II criteria, consisting of patients with $(48 \%)$ or without $(52 \%)$ a history of gastroenteritis. They found an increased density of 5-hydroxytryptatimine and substance $\mathrm{P}$ immunoreactive nerves surrounding mast cells in the ileum and colon of IBS patients. As there was no change in the density of calcitonin gene related peptide positive nerves, the findings unlikely reflect a generalised upregulation of nerves secondary to low grade inflammation. These data confirm the recent findings of Barbara and colleagues $^{24}$ showing close proximity of tryptase positive mast cells and nerves along with correlation of these intimate nerve to mast cell interactions with severity of abdominal pain in IBS patients. Taken together, these two independent studies from very different regions of the globe provide strong evidence supporting a role for neuroimmune interactions in IBS. The feasibility of such interactions is provided by previous demonstrations that substance $\mathrm{P}$, in low concentrations, can alter mast cell excitability ${ }^{26}$ and can directly influence mast cell function when released from nerves. ${ }^{27}$ These findings are in keeping with the demonstration that an increased rate of mast cell degranulation was found for mast cells located in close vicinity to nerves in the colonic mucosa of IBS patients. ${ }^{24}$ Interestingly, $\mathrm{T}$ lymphocytes may influence expression of neurokinin (NK)-1 receptors on mast cells and this may be important in the context of IBS where 
there is evidence of increased lymphocyte number ${ }^{21}$ and activation. ${ }^{28} \mathrm{~A}$ recent study has shown that the Th2 cytokine IL-4 upregulates NK-1 receptors on mast cells $\mathrm{s}^{29}$ and it is therefore possible that the Th polarity of intestinal immunity could influence the nature of neuroimmune interactions in IBS. As a Th2 immune response bias exists in countries where intestinal parasitic infection is endemic, ${ }^{30}$ it is possible that resulting changes in neuroimmune interactions could produce differences in the pathophysiology and clinical expression of IBS between Western and Eastern societies.

There is increasing recognition of the importance of infection in the pathogenesis of IBS, and the study of Wang and colleagues ${ }^{16}$ places this relationship in a broad global context. With emerging evidence supporting a role for inflammation and immune activation in IBS, studies are encouraged to address the influence of the microbial environment on the epidemiology and clinical expression of IBS across the globe.

Gut 2004;53:1068-1069.

doi: $10.1136 /$ gut.2004.038893

...................

Authors' affiliations

S M Collins, Intestinal Diseases Research Program, Division of Gastroenterology, McMaster University Medical Centre,

Hamilton, Ontario, Canada

G Barbara, Department of Internal Medicine and Gastroenterology, University of Bologna, Italy

Correspondence to: Professor S M Collins, Room 4W8, HSC, McMaster University Medica Centre, Hamilton, Ontario L8N 3Z5, Canada; scollins@.mcmaster.ca

\section{REFERENCES}

1 Martin BC, Ganguly R, Pannicker S, et al. Utilization patterns and net direct medical cost to Medicaid of irritable bowel syndrome. Curr Med Res Opin 2003·19.771-80

2 Rodriguez LA, Ruigomez A. Increased risk of irritable bowel syndrome after bacterial gastroenteritis: cohort study. BMJ 1999:318:565-6.

3 Gwee KA, Graham JC, McKendrick MW, et al. Psychometric scores and persistence of irritable bowel after infectious diarrhoea. Lancet 1996;347:150-3.

4 Gwee KA, Leong YL, Graham C, et al. The role of psychological and biological factors in postinfective gut dysfunction. Gut 1999;44:400-6

5 Ilnyckyi A, Balachandra B, Elliott L, et al. Posttraveler's diarrhea irritable bowel syndrome: a prospective study. Am J Gastroenterol 2003;98:596-9.

6 McKendrick MW, Read NW. Irritable bowel syndrome-post salmonella infection. $J$ Infect 1994;29:1-3.

7 Neal KR, Hebden J, Spiller R. Prevalence of gastrointestinal symptoms six months after bacterial gastroenteritis and risk factors for development of the irritable bowel syndrome: postal survey of patients. BMJ 1997;314:779-82.

8 Atoba MA. Irritable bowel syndrome in Nigerians. Dig Dis Sci 1988;33:414-16.

9 Lule GN, Amayo EO. Irritable bowel syndrome in Kenyans. East Afr Med J 2002;79:360-3.

10 Segal I, Walker AR. The irritable bowel syndrome in the black community. S Afr Med J 1984;65:72-3.

11 Tan YM, Goh KL, Muhidayah R, et al. Prevalence of irritable bowel syndrome in young adult Malaysians: a survey among medical students. J Gastroenterol Hepatol 2003;18:1412-16.

12 Lau EM, Chan FK, Ziea ET, et al. Epidemiology of irritable bowel syndrome in Chinese. Dig Dis Sci 2002;47:2621-4.

13 Kwan AC, Hu WH, Chan YK, et al. Prevalence of irritable bowel syndrome in Hong Kong. J Gastroenterol Hepatol 2002;17:1180-6.

14 Sinha P, Ghoshal UC, Choudhuri G, et al. Does Entamoeba histolytica cause irritable bowel syndrome? Indian J Gastroenterol 1997; 16:130-3

15 Barbara G, De Giorgio R, Deng Y, et al. Role of immunologic factors and cyclooxygenase 2 in persistent postinfective enteric muscle dysfunction in mice. Gastroenterology 2001;120:1729-36.

16 Wang L-H, Fang X-C, Pan G-Z. Bacillary dysentery as a causative factor of irritable bowel syndrome and its pathogenesis. Gut 2004;53:1096-1101.
17 Thornley JP, Jenkins D, Neal K, et al. Relationship of Campylobacter toxigenicity in vitro to the development of postinfectious irritable bowel syndrome. J Infect Dis 2001;184:606-9.

18 Lu CL, Chen CY, Lang HC, et al. Current patterns of irritable bowel syndrome in Taiwan: the Rome II questionnaire on a Chinese population. Aliment Pharmacol Ther 2003;18:1159-69.

19 Neal KR, Barker L, Spiller RC. Prognosis in postinfective irritable bowel syndrome: a six year follow up study. Gut 2002;51:410-13.

20 Gwee KA, Collins SM, Read NW, et al. Increased rectal mucosal expression of interleukin 1 beta in recently acquired post-infectious irritable bowel syndrome. Gut 2003;52:523-6.

21 Spiller RC, Jenkins D, Thornley JP, et al. Increased rectal mucosal enteroendocrine cells, $T$ lymphocytes, and increased gut permeability following acute Campylobacter enteritis and in post-dysenteric irritable bowel syndrome. Gut 2000:47:804-11.

22 O'Sullivan M. Clayton N, Breslin NP, et al. Increased mast cells in the irritable bowel syndrome. Neurogastroenterol Motil 2000;12:449-57.

23 Weston AP, Biddle WL, Bhatia PS, et al. Terminal ileal mucosal mast cells in irritable bowel syndrome. Dig Dis Sci 1993;38:1590-5.

24 Barbara G, Stanghellini V, De Giorgio R, et al. Activated mast cells in proximity to colonic nerves correlate with abdominal pain in irritable bowel syndrome. Gastroenterology 2004; 126:693-702

25 Dunlop S, Jenkins D, Spiller R. Distinctive histological patterns of chronic inflammatory cells in rectal biopsies of patients with different clinical subtypes of IBS. Gastroenterology 2002;122:A316

26 Janiszewski J, Bienenstock J, Blennerhassett MG Picomolar doses of substance $P$ trigger electrical responses in mast cells without degranulation. Am J Physiol 1994;267:C138-45.

27 Suzuki R, Furuno T, McKay DM, et al. Direct neurite-mast cell communication in vitro occurs via the neuropeptide substance P. J Immunol 1999; 163:2410-15.

28 Chadwick VS, Chen W, Shu D, et al. Activation of the mucosal immune system in irritable bowe syndrome. Gastroenterology 2002;122:1778-83.

29 van der Kleij HP, Ma D, Redegeld FA, et al. Functional expression of neurokinin 1 receptors on mast cells induced by IL- 4 and stem cell factor. J Immunol 2003; 171:2074-9.

30 Yazdanbakhsh M, Matricardi PM. Parasites and the hygiene hypothesis: regulating the immune system? Clin Rev Allergy Immunol 2004;26:15-24. 